\title{
Impact of clipping on root systems of 3 grasses species in Tunisia
}

\author{
MOHAMED CHAIEB, BELGACEM HENCHI AND MAKKI BOUKHRIS
}

Authors are professors, Department of Biology, Faculté des Sciences de Sfax - 3038 Sfax - Tunisia

\begin{abstract}
The study concerns the impact of herbivory on the root systems of 3 perennial grasses, buffelgrass (Cenchrus ciliaris), digitgrass (Digitaria commutata) and needlegrass (Stipa lagascae), growing in the arid zones of Tunisia. The study simulated animals feeding of the grasses by affecting cuttings at various times throughout the spring growing period. The following effects on the root systems of the grasses were observed.

When there is continual overgazing (simulated by cutting all sprouts down the ground level along the spring), more than $65 \%$ of the roots off all 3 species are found in the salty upper $15 \mathrm{~cm}$ of soil.

In case of medium average grazing (simulated by 2 to 3 cuttings), the root system again remains superficial for bufielgrass (C. ciliaris), with 58 to $67 \%$ of the roots located in the upper 15 cm of soil. Digitgrass (Digitaria commutata) and needlegrass (Stipa lagascae), however, develop deeper roots with 68 to $86 \%$ in the upper $30 \mathrm{~cm}$ of soil.

When grazing is light (just one cutting), all 3 species perform all most exactly as if there had been no grazing compared to (a control plot) with $85 \%$ of the root system located in the upper 50 $\mathrm{cm}$ and about $15 \%$ at 50 to $75 \mathrm{~cm}$ of ground depth.

On the basis of this experiments, it is suggested that grazing on these grasses should be allowed just once each spring, thereby allowing:

1- To take advantage of the aboveground contained in these grasses in spring.

2- Preservation of a deep root system wich will thereby have a much better chance of getting through the water stress summer season.
\end{abstract}

Key Words: perennial grasses, root system, arid zones, herbivory.

In arid zones, herbivory is a main factor affecting the survival, growth, competition, composition and reproduction of plants (Harper 1977, Whittaker 1979, Whittaker and Malloch 1980 , Owen and Wiegert 1981). In an environment where plant growth is linked to resource levels, it is important to evaluate the impact of herbivory overgrazing on plant life.

The high degree of complexity in the interaction of factors affecting plant growth calls for experimental work on the impact

Manuscript accepted 17 Aug 1995. of the herbivory (Hodgkinson and Baas Beching 1977). Little work has been done in North Africa, in relation to this phenomenen. That is why it is appropriate to assess the impact on the root systems of 3 perennial grasses, as simulated through cuttings made at various dates throughout the spring growing system.

\section{Materials and methods}

These experiments were made on buffelgrass (Cenchrus ciliaris), digitgrass (Digitaria commutata) and needlegrass (Stipa lagascae), 3 perennial grasses common to the arid zones of Tunisia. They were taken from a Rhanterium suaveolens plain and planted on an experimental plot $20 \mathrm{~km}$ east of Gabès in southern Tunisia. In this area, the annual rainfall is averaging 170-180 $\mathrm{mm}$, the minimal average temperature in the coldest month is $4-5^{\circ} \mathrm{C}$ while the maximum average temperature in the hottest month is $34-36^{\circ} \mathrm{C}$. The experimental site is located on a plain of alluvial origin, with fine sandy (60\%) soil. The calcium carbonate content is about $10 \%$, gypsum $2-4 \%$ and organic matter does not exceed $0.7 \%$. The physical and chemical characteristics of this experimental station is presented Table 1. Planting was done in October 1985 on experimental plots of $5 \mathrm{~m} \times 2 \mathrm{~m}$.

In each plot, the intervals of rows and the spacing of plants are $50 \mathrm{~cm}$. The number of plants per plots is 27 , and each plot contain a single species in 4 replications (Chaïeb 1989).

The grasses' establishment was made in 1985 with clumps' transplantation. Throughout the study period, we did not apply irrigation and fertilizer.

Throughout the year 1989-1990, the grasses were cut on different dates between 10/2/1990 and 10/4/1990. The same cutting treatments were applied for each species (Table 2). The annual rainfall registred throughout the year 1989-90, is given in Figure 1.

The cuttings were made at groundlevel, simulating grazing. For the continual cuttings, the clumps was maintained at groundlevel through cutting every 10 days, between 10/02 and 10/4/1990, and simulating overgrazing, characteristic of Tunisian arid zones. At the end of the month of May (6 weeks after the last cutting) the root systems of the grasses were observed using the crop profile method of Hénin and et Monnier (1969). This method is known by the term trench profil method. The trench width is $50 \mathrm{~cm}$ and the depth is $120 \mathrm{~cm}$. The samples (for measuring root density) were taken with a cylinder of $100 \mathrm{~cm}^{3}$ along the axis of the clumps. This procedure has a minimal risk of possible interference on rooting of the various types with regard to age (5 years). 
Table 1: Physical and chemical characteristics of soil study site

\begin{tabular}{|c|c|c|c|c|c|c|c|c|}
\hline \multirow[b]{2}{*}{ Depth } & \multicolumn{4}{|c|}{$\begin{array}{l}\text { Physical characteristics } \\
\text { (Granulometry } \mu \text { ) }\end{array}$} & \multicolumn{4}{|c|}{ Chemical characteristics } \\
\hline & $0-2$ & $2-20$ & $20-50$ & $50-200$ & OM & $\mathrm{CaCo}_{3}$ & $\mathrm{CaSo}_{4}$ & EC \\
\hline$\overline{(\mathrm{cm})}$ & & & & & $(\%)$ & $(\%)$ & (\%) & $\left(\mathrm{mS} . \mathrm{cm}^{-1}\right)$ \\
\hline $0-30$ & 6 & 10 & 23 & 61 & 0,7 & 9,8 & 2,0 & 1,3 \\
\hline $30-50$ & 7 & 9 & 23 & 61 & 0,5 & 11,5 & 3,2 & 1,6 \\
\hline $50-80$ & 6 & 9 & 24 & 61 & 0,3 & 9,6 & 2,0 & 1,6 \\
\hline
\end{tabular}

The distribution of the roots under the effect of the cuttings is expressed in 2 ways :

1-Descriptive root distribution: In which a profile description of the roots was accomplished; in this case, the roots extraction was done manually under a jet of water.

2-Quantitative root distribution: Samplings were taken from the soil at a depth betwen 0 and 75 centimeter(a sufficient depth for graminaceae) by means of $100 \mathrm{~cm}^{3}$ cylinder (having a diameter of $5 \mathrm{~cm}$ ). For each species and for each treatment, the depth intervals observed were: $0-5,5-15,15-30,30-50$ and $50-75$. At each depth interval, three $100 \mathrm{~cm}^{3}$ samplings $\left(3 \times 100 \mathrm{~cm}^{3}\right)$ were taken. Figure 2 shows the location of the different samplings. The percentage and the root density corresponding to each interval were calculated by the average of the 3 samplings. The root weight was determined after washing and drying of the roots at a temperature of $105^{\circ} \mathrm{C}$ and during 24 hours.

\section{Results}

\section{1-Descriptive Root Repartition}

As seen in figure 2, the total cutting is very harmful to all 3 grasses, the root systems tending to be superfical. The maximum root depth is about $30 \mathrm{~cm}$ for the 3 grasses. This depth increases when there are only 3 cuttings : the roots are seen in the 65 upper $\mathrm{cm}$ of the earth. With 2 cuttings in February and March, although some roots go down to $80 \mathrm{~cm}$ depth, the density at that depth is quite low, despite soil humidity during the spring growing season. Very little difference in the maximum root depth is noted

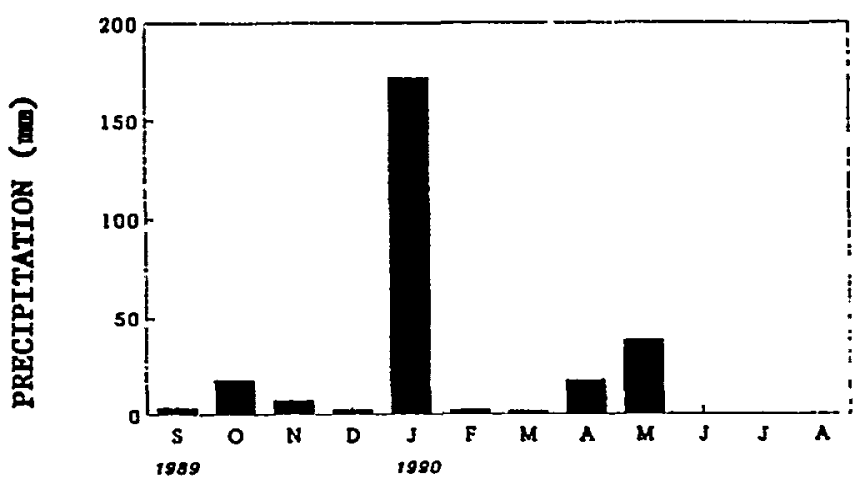

Fig. 1. Monthly precipitation at experimental station from September 1989 to August 1990. between those grasses cut only once in the spring and the control plots which were not cut at all. In both cases, root depth varies from 100 to $110 \mathrm{~cm}$. Nor is much difference to be seen in the development of the upper growth between the control plot and the grasses cut just once.
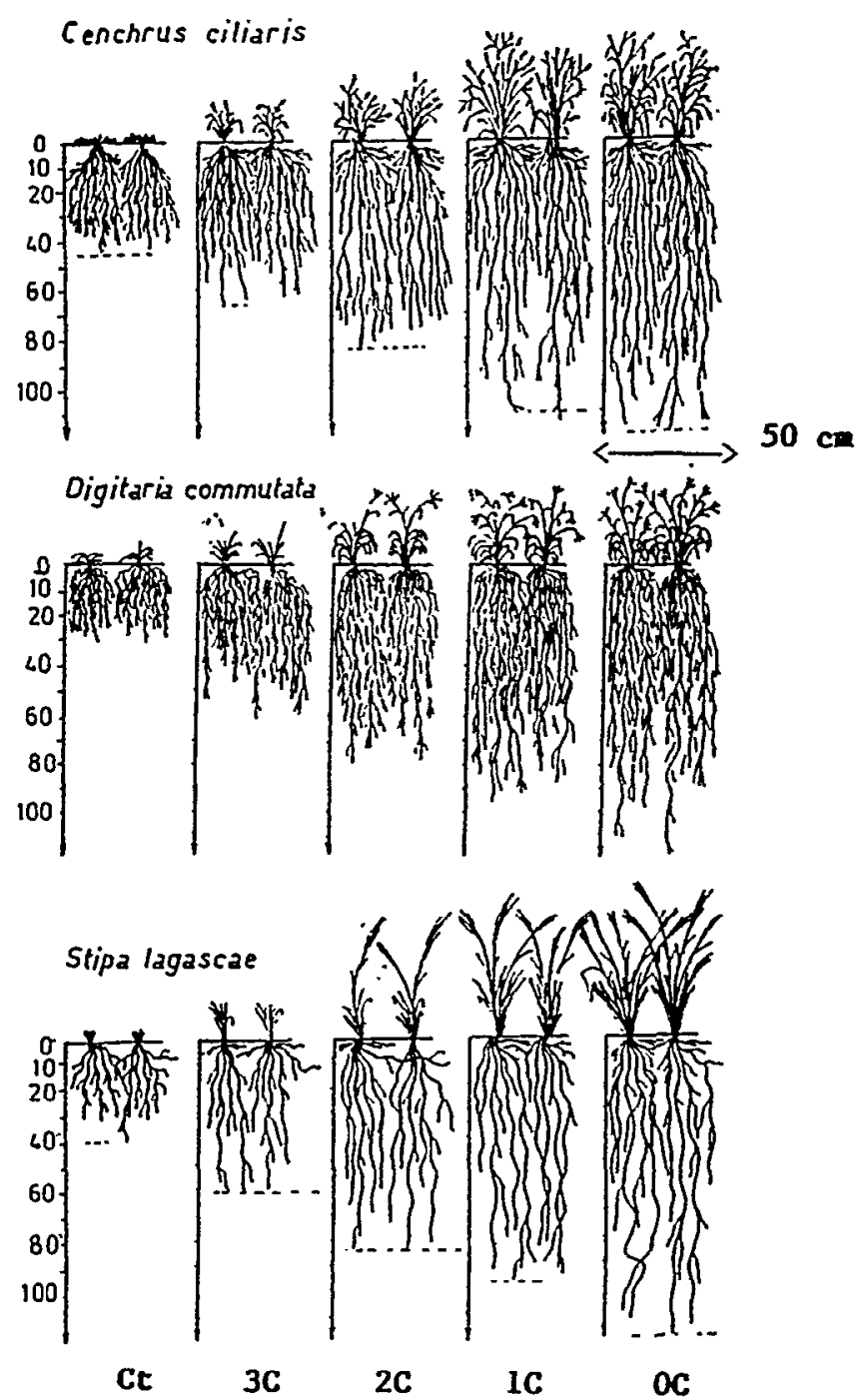

Fig. 2. Rooting patterns of roots of 3 perennial grasses in May 1990 , after imposition of clipping continously at 10-days intervals (Ct), clipping in February, March and April 1990 (3C), February and March (2C), March (1C) or no clipping (OC) in southern Tunisia. 
Table 2: Dates and number of cuttings

\begin{tabular}{lccccc}
\hline \hline Treatments & Control plot & & Number of cut & & Continual cutting \\
& $(0 \mathrm{C})$ & IC & $2 \mathrm{C}$ & $3 \mathrm{C}$ & (CC) \\
\hline Date of cutting & not cut & $10 / 2 / 90$ & $10 / 2 / 90$ & $10 / 2 / 90$ & every 10 days between \\
& & & $10 / 3 / 90$ & $10 / 3 / 90$ & $10 / 2$ and $10 / 4 / 90$ \\
& & & $10 / 4 / 90$ & & \\
\hline
\end{tabular}

\section{2-Quantitative Root Distribution}

Soil samplings taken from cut grasses show that in the case of simulated continual clipping occurring every 10 days, the root system remains very superficial, varying for the different grasses from 60 to $80 \%$ of the roots located in the upper $15 \mathrm{~cm}$ of earth, whereas at $30-50 \mathrm{~cm}$ depth, roots are present at a rate of $10 \%$ for buffelgrass (C. ciliaris) and needlegrass (S. lagascae) and $30 \%$ for digitgrass (D. commutata) (Fig. 3 ).

Those grasses cut 3 times $(3 \mathrm{C})$ in spring show root behavior very similar to those of grasses cut regularly every 10 days for buffelgrass $(C$. ciliaris) and digitgrass ( $D$. commutata). At a depth of $0-50 \mathrm{~cm}$, roots are found at rates identical to the 2 other regimes, for both grasses. Furthermore, between 50 and $75 \mathrm{~cm}$, the 2 species develop roots at a rate under 3\%. Needlegrass ( $S$. lagascae) cut 3 times ( $3 \mathrm{C}$ ) in succession grows much more roots than when continually cut, with $28.5 \%$ of the roots located at a 30 $\mathrm{cm}$ depth and only $12.7 \%$ at the same depth for those cut regularly (every 10 days).

For all 3 grasses, little quantitative differences are noted between the control plot and the one-cutting plot. The rooting rate is about the same throughout. Nevertheless it is important to mention that the difference is less clear for digitgrass (D. commutata), which seems most resistant to the cutting but with more superficial rooting than the other species (Fig. 3).

These observations are reflected in root density (Fig. 4), expressed in mg.dry matter per $\mathrm{cm}^{3}$ where very low density is found for all three species beyond $30 \mathrm{~cm}$ depth, particularly for the continual cutting. The highest density is observed for the noncut grasses (control plot), especially buffelgrass ( $C$. ciliaris) and needlegrass ( $S$. lagascae). Those grasses cut only once have high density across the board; for digitgrass ( $D$. commutata), density is even higher than that of the control plot.

\section{Discussion and Conclusions}

A knowledge of plant root systems under manipulation is very useful for rangeland management. The complexity of its structure is directly related to the degree of manipulation (Whittaker and Malloch 1980, Dirzo 1985). The experiments undertaken show the effect of repeated cuttings: the more cuttings, the more superficial the root system. Monroy-Ata (1989) considers herbivory one of factors natural selection, with resistance depending on the given plant. This line of thinking must take into account 2 major elements : intensity of the herbivory and of the spacial-temporal availability of ressources. When resources are available, the root system at the lower level will have a great dynamism, thus guaranting regrowth (Kummerow pers. comm.) when, however, resources are scarce, heavy animal pressure will have a physiological effect, characterized by Crawley (1987) as unavoidable in so far as the absence of any migratory reserves at the heavily browsed upper growth prevents rhizo-genesis. Thus the location of surface roots, as affected by repeated cuttings, exposes the plant to water stress in the upper layers, potentially menacing its survival particularly during summer drought.
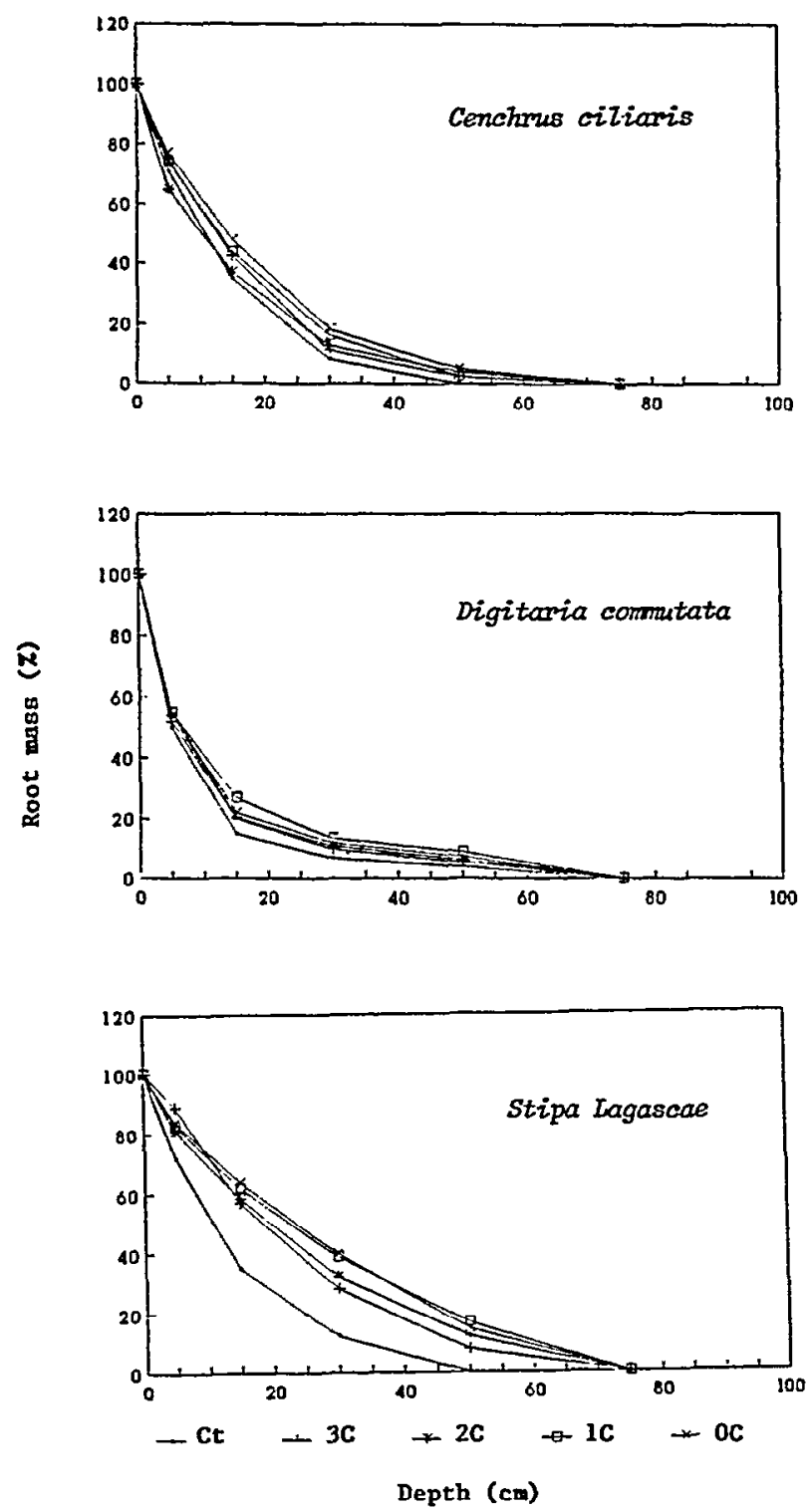

Fig. 3. Cumulative root distributions of 3 perennial grasses in May 1990, after imposition of clipping continously at $\mathbf{1 0}$-day intervals (Ct), clipping in February, March an April 1990 (3C), February and March (2C), March (1C), or no clipping (0C) in southern Tunisia, expressed as the percent of total oven-dry root mass in 5 depth increments. 

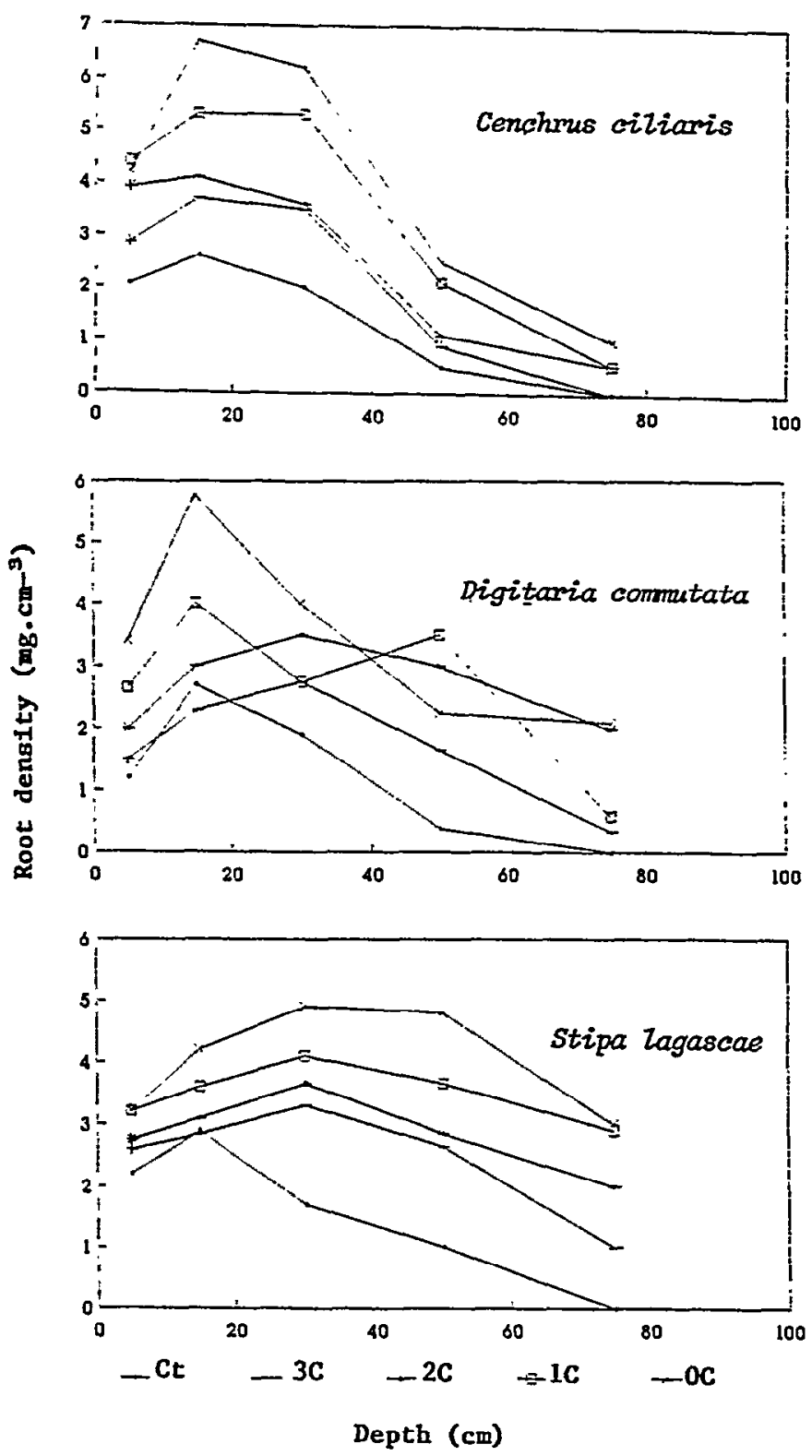

Fig. 4. Root mass per unit soil volume of 3 perennial grasses in May 1990, after imposition of clipping continously at 10-day intervals (Ct), clipping in February, March, and April 1990 (3C), February and March (2C), March (1C), or no clipping (OC) in southern Tunisia, expressed as percent of total oven-dry root mass in 5 depth increments.

Since we do not see much variance in the structure of root systems from the control plot and the one-cut, it is considered that one sole grazing in spring will not have much incidence on its growth. This grazing must, of course, be allowed only after plant growth is completed, after total seed dispersal.

These findings must be taken with caution. More information on the impact of herbivory on plant root systems could be obtained by further experimentation, preferably under field conditions.

\section{Literature Cited}

Chaieb, M. 1989. Influence des réserves hydriques du sol sur le comportement comparé de quelques espèces végétales de la zone aride tunisienne. Thèse de Doctorat, Université de Montpellicr II, 298 p.

Crawley, M.J. 1987. Benevolent herbivores? Trends in Ecology and Evolution 2:167 - 168 .

Dirzo, R. 1985. The role of the grazing animal. p. 343-355. In: J.L. Harper (eds), Studies on Plant Demography. Academic Press, London.

Harper, J. L. 1977. The Population Biology of Plants. Academic Press, London.

Henin, S., Gras, and R.G et Monnier. 1969. Le profil cultural. Masson and Co, Paris.

Hodgkinson, K. C. and H.G. Baas Beching. 1977. Effect of Defoliation on Root Growth of Some Arid Zones Perennial Plants. Aust. J. Agr. Res. 29: 31-42.

Monroy-Ata, A. 1989. Installation des plantes pérennes de la zone aride soumises à des contraintes hydriques contrôlées et à des coupes. Thèse de Doctorat, Université de Montpellier I, 178 p.

Owen, D. F. and R.G. Wiegert. 1981. Mutualism betwen grasses and grazers: an evolutionary hypothesis. Oikos 36: 376-378.

Whittaker, J. B. 1979. Invertebrate grazing: Competition and plant dynamics, p. 207-222. In: O. T. Solbrig (eds), Population Dynamics, Blackwell Sci. Publ. Oxford.

Whittaker, J. B. and A.J.C. Malloch 1980. Field experiments on the effects of grazing by a chrysomelid beetle (Gastrophysa viridula) on sced production and quality in Rumex obtusifolius and Rumex crispus. J. of Ecology, 68: 671-674.

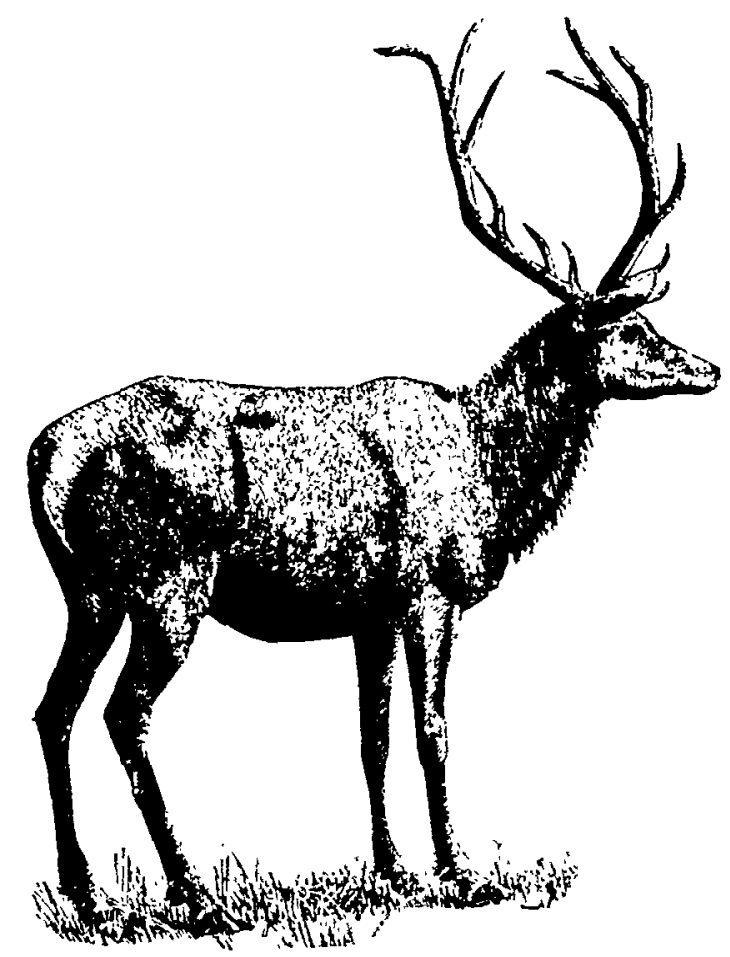

